\title{
Can a single lactate value predict adverse outcome in critically ill newborn?
}

\author{
Simovic $\mathrm{A}^{1,2}$, Stojkovic $\mathrm{A}^{1,2}$, Savic $\mathrm{D}^{1,2}$, Milovanovic $\mathrm{DR}^{2,3}$ \\ Paediatric Clinic, Clinical Centre, Kragujevac, Serbia. aleksandra.simovic@yahoo.com
}

\begin{abstract}
OBJECTIVES: The aim of this study was to investigate the role of the lactic acidosis, as an early predictor of significant consequences and/or a fatal outcome in term neonates after a perinatal asphyxia.

BACKGROUND: Severe perinatal asphyxia can generate multiple organ dysfunction and neonatal mortality. METHODS: In routine clinical practice, after an admission to the Intensive Care Unit, lactate concentration was determined in capillary blood samples during the first one to six hours after birth in 55 term newborns with the post-asphyxial hypoxic-ischemic encephalopathy. The control group consisted of 36 healthy term neonates randomly selected in the maternity ward at the Gynecology and Obstetrics Clinic.

RESULTS: Significantly higher concentrations of lactate $(p<0.0005)$ were observed in term neonates with post asphyctic syndrome $(8.63 \pm 4.43 \mathrm{mmol} / \mathrm{L})$ if compared to the control group subjects $(1.04 \pm 0.36 \mathrm{mmol} / \mathrm{L})$. The increase in lactate level $>8.7 \mathrm{mmol} / \mathrm{L}$ with $80 \%$ sensitivity and $82 \%$ specificity indicated the development of the hypoxic-ischemic encephalopathy stage II/III, while the lactate level $>9.95 \mathrm{mmol} / \mathrm{L}$ was a predictor of death, with $75 \%$ sensitivity and $74.4 \%$ specificity.

CONCLUSION: Determination of lactate concentrations in serum of term newborns associated with risk factors for the perinatal asphyxia is a useful tool in diagnosing metabolic disorders and ischemic damage, particularly severe clinical forms (Tab. 2, Fig. 3, Ref. 34). Text in PDF www.elis.sk.

KEY WORDS: oxidative stress, respiration, artificial, respiratory distress syndrome, newborn.
\end{abstract}

\section{Introduction}

Perinatal asphyxia (PA) is the medical condition of impaired gas exchange before, during or shortly after birth, which - if continuing - may cause a progressive decrease in the partial pressure of oxygen, and an increase in partial pressure of carbon dioxide, associated with a drop in blood $\mathrm{pH}$. It is the second leading cause of neonatal morbidity and mortality, after prematurity (1-3). The PA incidence varies depending on diagnostic criteria. According to the research in developed countries, the incidence of severe $\mathrm{PA}$, (which leads to significant neurological sequelae or death) is about $1 / 1000$ live births $(4,5)$, while the PA occurs more often in underdeveloped countries. In hospitalized children, it ranges from 5-10/1000 live births, but the data come from developed countries and probably underestimate the actual incidence of perinatal asphyxia in underdeveloped areas $(5,6)$.

Pathophysiological basis of post-asphyctic lesions in some organs and tissues resulted from an exhausted mechanism of

${ }^{1}$ Paediatric Clinic, Clinical Centre, Kragujevac, Serbia, ${ }^{2}$ Faculty of Medical Science, University of Kragujevac, Serbia, and ${ }^{3}$ Department of Clinical Pharmacology, Clinical Centre, Kragujevac, Serbia

Address for correspondence: A. Simovic, MD, PhD, Paediatric Clinic, Clinical Centre “Kragujevac”, Zmaj Jovina 30, 34000 Kragujevac, Serbia. Phone: +381.34.370097, Fax: +381.34.370213

Acknowledgements: This paper is based upon the doctoral dissertation produced by Dr Aleksandra Simovic, which was successfully defended at the Faculty of Medical Science - University of Kragujevac on 7 April 2011. circulatory and metabolic adjustments of newborn to hypoxicischemic stress. Fundamental initial vascular changes in hypoxia are vasoconstriction, reducing blood flow through so-called 'peripheral' vascular regions (kidneys, gastrointestinal tract, skin and muscles), increased systemic blood pressure, and maintenance of the blood supply to the brain, myocardium and the adrenal glands. Later, during circulatory decompensation, there are myocardial workload and a reduced blood inflow to the right atrium, reduction in cardiac output, systemic hypotension and a development of ischemia in all organs $(7,8)$.

In addition to the vascular compensatory response to hypoxia, there are also metabolic changes. Anoxia activates anaerobic glycolysis with a consequently reduced synthesis of adenosine triphosphate and lactate accumulation. In the event of depletion of the glycogen stores, an accelerated catabolism of energy-rich purine bases occur $(8,9)$ and therefore, hypoxanthine and uric acid accumulate. Reduction of the adenosine triphosphate stores produces severe effects for the weakening of energy-dependent cation transport system (sodium, calcium, potassium), membrane phospholipid disorder and free fatty acids disorder, and the accumulation of various harmful metabolites such as prostaglandins, leukotrienes and free radicals, which lead to further cell damage (9).

In recent years, there has been a great interest in the application of biochemical markers in the assessment of post-asphyctic lesions. In this sense, a so-called 'Biochemical Apgar score' has been suggested for an immediate evaluation of hypoxic-ischemic insult $(8,9)$. In addition, more and more attention is paid to their 
Tab. 1. Characteristics of the study group.

\begin{tabular}{|c|c|c|c|}
\hline Clinical characteristics $(\mathrm{n}=161)$ & Term neonates with PA & Term neonates without PA & $\mathrm{p}$ \\
\hline Male (\%) & $31 / 55(56.36)$ & $17 / 36(47.22)$ & $>0.05$ \\
\hline Female (\%) & 24/55 (43.64) & 19/36 (52.78) & $>0.05$ \\
\hline $\mathrm{GW}(\mathrm{x} \pm \mathrm{SD})$ & $39.5 \pm 1.32$ & $39.8 \pm 1.089$ & $>0.05$ \\
\hline BW kilogram $(\mathrm{x} \pm \mathrm{SD})$ & $3.4298 \pm 0.571$ & $3.455 \pm 0.352$ & $>0.05$ \\
\hline AS in 5 minute $(x \pm S D)$ & $4.704 \pm 2.186$ & $8.94 \pm 0.41$ & $<0.005$ \\
\hline Vaginal delivery (\%) & $36 / 55(65.45)$ & $36 / 36(100)$ & $>0.05$ \\
\hline Caesarean section (\%) & $19 / 55(34.54)$ & $0 / 36(0)$ & $<0.005$ \\
\hline Vacuum extraction (\%) & $5 / 55(9.09)$ & $0 / 36(0)$ & / \\
\hline Resuscitation (\%) & $40 / 55(72.73)$ & $0 / 36(0)$ & $<0.005$ \\
\hline Duration of oxygen therapy - days $(\mathrm{x} \pm \mathrm{SD})$ & $15.46 \pm 17.27$ & 0 & / \\
\hline Duration of oxygen therapy $>28$ days & 8/55 (14.54) & $0 / 36(0)$ & / \\
\hline MV (\%) & $31 / 55(56.36)$ & $0 / 36(0)$ & $<0.005$ \\
\hline Duration of mechanical ventilation -days ( $\mathrm{x} \pm \mathrm{SD}$ ) & $5.679 \pm 8.419$ & 0 & 1 \\
\hline Inotropic therapy (\%) & 23/55 (41.82) & $0 / 36(0)$ & $<0.005$ \\
\hline Dead (\%) & $13 / 55(23.64)$ & $0 / 36(0)$ & I \\
\hline
\end{tabular}

$\mathrm{n}$ - number of patients, PA - perinatal asphyxia, GW - Gestational week, BW - Birth weight (in kg), AS - 5-min Apgar score, MV - conventional mechanical ventilation, $\mathrm{x} \pm \mathrm{SD}-$ mean \pm standard deviation

possible role as early indicators of significant neurological sequelae and possible death in critically ill neonates (10-15). Since there is still no consensus concerning the importance of lactate as a predictor of outcome following the PA, the main goal of this paper is to investigate the relationship between the serum concentration of this metabolite in early postnatal period and later adverse outcomes in this population of infants.

\section{Materials and methods}

The study was designed as diagnostic and prognostic research in conditions of real clinical practice. It was approved by a written parental consent and a decision by the Clinical Ethics Committee.

During the three-year study (August 2007 - January2010), 108 subjects were followed, 17 of which being excluded, because of the presence of diseases and conditions with serious hyperlactatemia, such as: congenital heart disease (5), chromosomal aberrations (3) or conatal sepsis (9). Data were analysed for 91 patients (55 with post-asphyctic syndrome and 36 healthy term newborns). Clinical diagnosis of the PA in our study was based on previously published criteria (16-21) such as: a) medical history of foetal asphyxia and/ or gynecologic-obstetric complications, b) cardio-respiratory and neurological depression defined as Apgar score $<4$ at $1 \mathrm{~min}$ and $<7$ at 5 minute after birth, c) metabolic acidosis defined as lactate level $>3.7 \mathrm{mmol} / \mathrm{l}$ in the first 1-6 hours after birth, at admission to emergency department d) respiratory distress) seizures < 48 hours, hypotonia or coma; f) hypotension and/or oliguria; g) multiple organ insufficiency.

The analysed variables were as follows: a) pregnancy (normal or complicated), b) delivery (vaginal delivery, Caesarean section), c) birth weight (in kilogram), d) gestational age, (within the first 1-6 hours after birth and based on morphological and neurological criteria proposed by Dubowittz in 1970 and by Ballard in 1979), e) 5-minute Apgar score (clinical assessment of the neonatal viability proposed by V. Apgar in 1953), f) the lactate level within the first 1-6 hours after birth was measured in capillary blood sample using the GEM Premier 3000 analyser (The reference range for lactate was 0.3-3 mmol/l) g) hypoxic-ischemic encephalopathy (HIE), (defined as proposed by three-stage Sarnat score in 1976) (22) present on first neurological examination within 12 hours after birth, h) application of conventional ventilation. Absolute indication for conventional ventilation was hypoxemia $\mathrm{paO}_{2}<$ $50 \mathrm{mmHg}$ or $6.65 \mathrm{kPa}$ at $\mathrm{FiO}_{2}>0.8$, hypercapnia $\mathrm{paCO}_{2}>8.0$ $\mathrm{kPa}$ or $60 \mathrm{mmHg}, \mathrm{pH}<7.2$, and apnea longer than 20 seconds, according to the criteria of Gligorovic 1995 (7), and i) application of inotropes. The maintenance of arterial tension was below the 10th percentile for a given gestational age and birth weight and/ or oliguria $<1 \mathrm{ml} / \mathrm{kg} / \mathrm{h}$, despite colloidal volume replacement solutions, was the indication for application of inotropes, according to the criteria of Cruz et al in 2006 (23); j) death.

\section{Statistical analysis}

Clinical characteristics of the subjects were summarized using descriptive statistics-mean, standard deviation, median and percentiles. Mann-Whitney test was used for comparison of the mean values between the two populations. Prognostic significance of biomarkers was investigated by the evaluation of test performance (sensitivity and specificity).

\section{Results}

Baseline clinical characteristics observed across the groups are shown in the Table 1. Abnormal pregnancy occurred in 38 (69.1\%) term neonates with the PA (experimental group) and it was normal in 17 subjects (30.9\%). The most common perinatal risk factors in this group are shown in the Table 2. Serum lactate concentration was $8.63 \pm 4.43 \mathrm{mmol} / \mathrm{l}$ (mean \pm standard deviation), median 7.6 with range $4.8-13.3 \mathrm{mmol} / \mathrm{l}$ (Fig. 1). The HIE grade 1was registered in 23 (41.82 \%), the HIE grade 2 in 21 (38.18 $\%)$, and the HIE grade 3 in 11 (20\%) patients. Lactate threshold ('cut-off') of $8.7 \mathrm{mmol} / \mathrm{l}$ was an early indicator of HIE grade 2-3, with $80 \%$ sensitivity and $82 \%$ specificity, PPV $42.1 \%$ and NPV $93.7 \%$ (area $=0.853, \mathrm{p}<0.0005$ ) (Fig. 2). The outcome was fatal in $13(23.64 \%)$ patients, and the early increase in lactate $>9.95$ 
Tab. 2. Risk factors for perinatal asphyxia in experimental group.

\begin{tabular}{lc}
\hline Risk factors for perinatal asphyxia & Value (\%) \\
\hline Pre-eclampsia & $4 / 55(7.27)$ \\
Other diseases in pregnancy & $4 / 55(7.27)$ \\
Fetal malpresentation & $3 / 55(5.45)$ \\
Tocolytic therapy & $2 / 55(3.63)$ \\
Twins & $1 / 55(1.82)$ \\
Premature rupture of membranes & $3 / 55(5.45)$ \\
Meconial amniotic fluids & $14 / 55(25.45)$ \\
Pathological cardiotocography - bradycardia & $13 / 55(23.63)$ \\
Placental abruption & $1 / 55(1.82)$ \\
Umbilical cord prolapse and/or compression & $12 / 55(21.81)$ \\
Meconium aspiration & $6 / 55(10.9)$ \\
Other risk factors for perinatal asphyxia & $2 / 55(3.63)^{*}$ \\
*1-perinatal trauma/1-congenital diaphragmatic hernia &
\end{tabular}

$\mathrm{mmol} / \mathrm{l}$ was a predictor of death with $75.0 \%$ sensitivity and 74.3 $\%$ specificity, PPV $47.4 \%$ and NPV of $90.6 \%$ (area $=0.797$, p $=0.002$ ) (Fig. 3).

In term newborns without the PA (control group): all subjects had normal pregnancy and delivery; they were without clinically manifest disease and with normal neurological findings. Serum lactate concentration was $1.04 \pm 0.36 \mathrm{mmol} / \mathrm{l}$ (mean \pm standard deviation), median 0.9 with the range $0.8-1.2 \mathrm{mmol} / \mathrm{l}$ (Fig. 1).

\section{Discussion}

Blood lactate levels are frequently measured, usually to detect tissue hypoxia (24-27). However, the blood lactate monitoring in critically ill patient remains controversial considering the risk assessment. Some of the discrepancy is due to an uncertainty regarding the appropriate reference interval, whether to perform a single lactate measurement or serial lactate measurements as a screening method of critically ill patient $(25,26,28)$. Furthermore, there is no consensus whether the sample should be drawn from the arterial, peripheral venous, or capillary blood. Most investigators found a satisfactory agreement comparing capillary or venous lactate levels

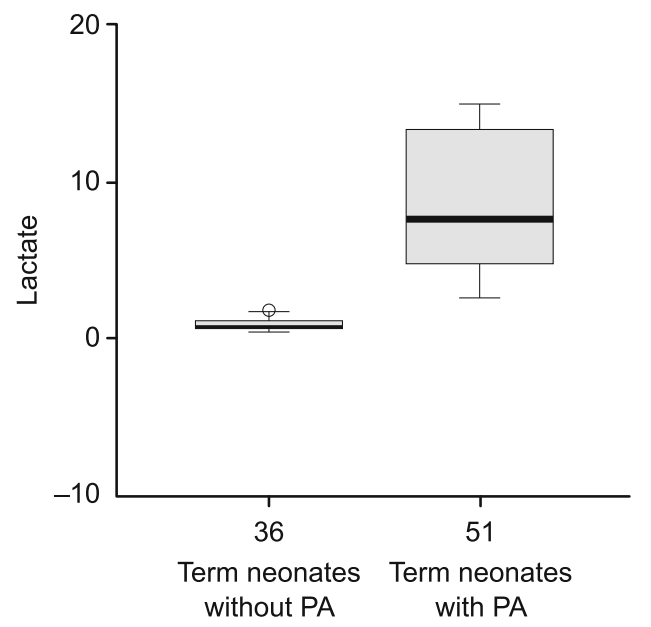

Fig. 1. The mean and standard deviation of blood lactate levels ( $\mathrm{mmol} / \mathrm{l})$ in neonates with and without perinatal asphyxia (PA).

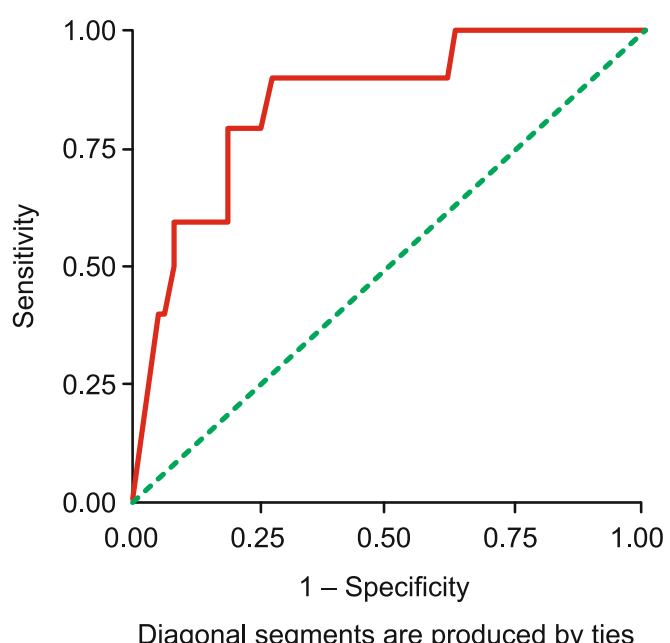

Fig. 2. Predictive value of lactate for the occurrence of moderate-tosevere hypoxic ischemic encephalopathy: sensitivity and specificity.

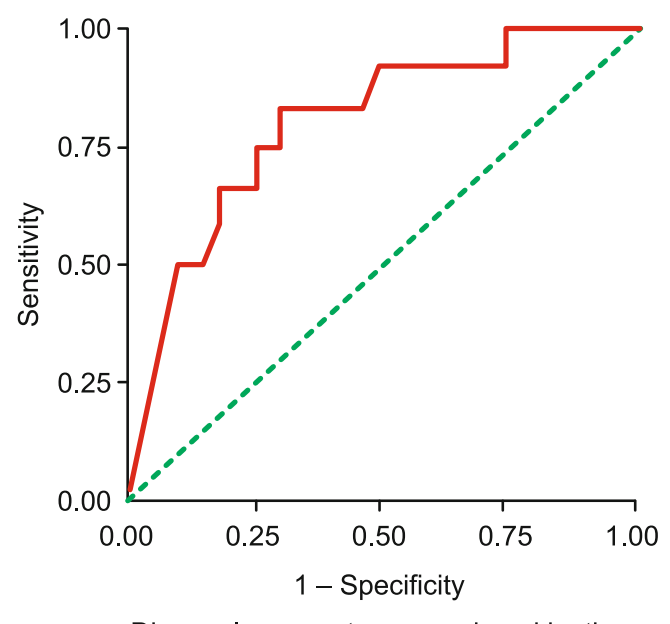

Diagonal segments are produced by ties

Fig. 3. Predictive value of lactate for early mortality in term newborns with perinatal asphyxia: sensitivity and specificity.

with arterial levels (25-28). In our opinion, such sampling should therefore be encouraged as patient undergoes this procedure with a minimal risk and inconvenience.

In our study, we analysed the prevalence of risk factors for the PA in term neonates and prognostic value of lactate concentrations, especially severe manifestations such as HIE and mortality. Generally, the pattern of risk factors was similar to the majority of previously published studies, whereas certain differences were observed in the diagnostic and prognostic values of the blood lactate. Therefore, further studies should be conducted in this area specifically directed to particular subpopulations of newborns, where threshold value for lactate, allowing an optimal relation between sensitivity and specificity in evaluation of clinical outcomes, would be identified more precisely.

The PA may occur in utero, during delivery or shortly after birth, so that all the risk factors can be classified into antenatal 


\section{1-595}

(20-25\%), intrapartal (35-40\%) and postnatal (35-40\%) (7, 9, $13,14)$. In our study, the most common symptom of the PA was green or meconial amniotic fluid (symptom of foetal distress) and foetal bradycardia was a risk factor in about a quarter of subjects. Other antenatal risk factors for the PA emerged with individual frequency in about every twentieth child or less: abnormal foetal presentation, premature rupture of the foetal membranes, application of tocolytics, multiple pregnancy and congenital diaphragmatic hernia. Pregnancy diseases were also not common, and the most common one was pre-eclampsia, occurring in about every 14 th pregnant women. It was followed by pregnancy-induced hypertension, severe anemia, hyperthyroidism and myasthenia gravis, with an overall incidence of $7.27 \%$. On the other hand, intrapartal risk factors (separately or associated with antenatal factors) were significantly more frequent in our study: the umbilical cord prolapse and/or compression (1 out of 5 infants), meconium aspiration and vacuum extraction, followed by varying degrees of birth trauma (every tenth case), and less frequent placental abruption.

Systemic effects of the PA at birth were accompanied by various clinical manifestations. In our study, the mean 5-minute Apgar score (score of cardio-pulmonary and neurological function) in term neonates with the PA was, as expected, much lower than in the control group. Delayed initiation of respiration at birth when primary resuscitation is needed (volume-controlled ventilation, insufflations of oxygen, chest cardiac massage and/or use of vasoactive drugs) was registered in nearly three quarters of subjects, while more than half of the asphyctic term infants and no subjects in the control group needed secondary resuscitation and the conventional mechanical ventilation. Nearly one in seven newborns required a prolonged mechanical ventilation and/or oxygenation therapy for $>28$ days. These subjects showed the HIE grade 3 followed by the significant neurological sequelae (coma). Also, inotropic drugs were administered significantly more frequently to asphyctic newborns (about two-fifths of subjects) if compared to the control group (without such therapy). The main reason for administration of inotropes, as in other studies, was hypotension, which, if associated with hypovolemia and lactacidosis, increases oxygen consumption and further reduce cardiac contractility $(7,9,23)$.

Monitoring of the lactate concentrations in serum may be a useful indicator of metabolic status of the newborns. Under normal circumstances, blood lactate levels in healthy term newborns exhibit a slow decline, from about $2.7 \mathrm{mmol} / \mathrm{l}(1.5-4.5 \mathrm{mmol} / \mathrm{l})$ in the first minute to $1.0 \mathrm{mmol} / \mathrm{l}(0.8-1.2 \mathrm{mmol} / \mathrm{l})$ during the first 24 hours, which is similar to the values obtained in our study (29). Several studies have suggested different values of this metabolite as a limit for particular manifestations of metabolic disorders and ischemic organ lesion, but no consensus has been reached. While for the mildest form (postnatal lactacidosis), it is almost certainly known that it begins with lactate concentration of $2.5 \mathrm{mmol} / \mathrm{l}$ (7, 9, 10-12), a much larger range between 3.7 (30) and $4.8 \mathrm{mmol} / \mathrm{l}$ (31) was the proposed threshold ('cut-off') of the PA.

Our results indicate that a precise classification of severe forms of the PA according to serum lactate depends considerably on the desired diagnostic accuracy. It is almost certain that postnatal lactate level less than $5 \mathrm{mmol} / \mathrm{l}$ is never associated with major neu- rological disorders $(10,11,28,30-33)$. However, the increase in lactate concentration taken as a diagnostic threshold value gives rise to sensitivity at the cost of specificity, and vice versa.

Actually, in previous studies, it was shown that lactate concentration in the term newborns which is in first 24 hours $>7.5$ $\mathrm{mmol} / \mathrm{l}$ with $94 \%$ sensitivity and $67 \%$ specificity may indicate the development of the HIE $(10,11,29-31)$ and that an early increase in lactate in severe asphyxia $>15 \mathrm{mmol} / \mathrm{l}$ was a sure indication of serious consequences or death with $100 \%$ sensitivity of and $88 \%$ specificity $(11,26,28,29)$. On the other hand, our results showed that somewhat higher lactate concentration indicated the development of more advanced stages of the HIE (with slightly lower sensitivity and higher specificity), but even significantly lower lactate concentration levels than previously suggested were highly sensitive indicators of death.

The results of our study should be interpreted bearing in mind the design limitations. Firstly, the Department of Neonatology in our Clinic admits both newborns and remote maternity hospitals, and samples for gas analysis were collected within the first 1-6 hours after birth. Since it was a non-interventional study, we could not take samples of the umbilical arterial blood, but arterialized capillary samples were taken at admission to the intensive care unit. On the other hand, during the primary resuscitation and/or transportation, a number of subjects received intravenous bicarbonate, which made it difficult to diagnose metabolic acidosis. According to the literature, lactate load remains longer in the circulation and varies less in relation to $\mathrm{pH}$ and base excess when bicarbonate is administered $(25,26)$. In numerous studies it has also been identified as a sensitive predictive factor (28-34).

\section{Learning points}

The rise of capillary blood lactate level can indicate the development of severe hypoxic-ischemic encephalopathy or the mortality outcome.

A speed increase of blood lactate is a sensitive predictive factor of severe ischemic damage of brain because it load remains longer in the circulation and varies less in relation to $\mathrm{pH}$ and base excess when bicarbonate is administered.

Monitoring of lactate concentrations next to the clinical picture of asphyctic newborn infants over time alow a more accurate determination of severe degree of hypoxaemia and the risk of the mortality outcome than a predefined absolute threshold.

\section{Conclusions}

The results of our study confirmed that monitoring of the lactate concentrations in the term newborns along with the risk factors for the PA is a useful method in diagnosing metabolic disorders and ischemic damage, especially in severe clinical forms. However, they suggested that the determination of the parameter dynamics over time along with the overall clinical picture of asphyctic newborn infants was probably much more accurate than a predefined absolute threshold. In this regard, further research is needed. 


\section{References}

1. Thornberg E, Thiringer K, Odeback A, Milsom I. Birth asphyxia: incidence, clinical course and outcome in a Swedish population. Acta Paediatr 1995; 84 (8): 927-932.

2. Airede Al. Birth asphyxia and hypoxic-ischaemic encephalopathy: incidence and severity. Ann Trop Paediatr 1991; 11 (4): 331-335.

3. Oswyn G, Vince JD, Friesen H. Perinatal asphyxia at Port Moresby General Hospital: a study of incidence, risk factors and outcome. P N G Med J 2000; 43 (1-2): 110-120.

4. Levene ML, Kornberg J, Williams TH. The incidence and severity of post-asphyxial encephalopathy in full-term infants. Early Hum Dev 1985; 11 (1): 21-26.

5. Boithias-Guerot C, Castel C, Dubois C, Zupan-Simunek V, Vial M. Orientation after peripartum asphyxia in the maternity word: wish infants chould be transferred to pediatric care units? J Gynecol Obstet Biol Reprod 2003; 32 (1): 91-97.

6. MacLennan A. A template for defining a causal relation between acute intrapartum events and cerebral palsy: international consensus statement. BMJ 1999; 319: 1054-1059.

7. Gligorovic S. Perinatal asphyxia and reanimation. Belgrade. School of Medicine, University of Belgrade, 1995.

8. Jankovic B, Marjanovic B. Neonatal hypoxic-ischemic encephalopathy. Acta Med Pediatr 1997; 5: 317-325.

9. Fanaroff A, Martin R. Neonatal Perinatal Medicine. Dis Fet Infant 2002; 7 (1): 420.

10. Da Silva S, Hennebert N, Denis R, Wayenberg JL. Clinical value of a single postnatal lactate measurement after intrapartum asphyxia. Acta Pediatr 2000; 89 (3): 320-332.

11. Shah S, Tracy M, Smyth J. Postnatal lactate as an Early Predictor of Short-Term Outcome after Intrapartum Asphyxia. J Perinatol 2004; 24: 16-20.

12. McAuliffe F, Mears K, Fleming S, Grimes H, Morrison JJ. Fetal cardiac troponin I in relation to intrapartum events and umbilical artery pH. Am J Perinatol 2004; 21 (3): 147-152.

13. Badawi N, Kurinczuk JJ, Keogh JM et al. Antepartum risk factors for newborn encephalopathy: the Western Australian case-control study. BMJ 1998; 317 (7172): 1549-1553.

14. Badawi N, Kurinczuk JJ, Keogh JM et al. Intrapartum risk factors for newborn encephalopathy: the Western Australian case-control study. BMJ 1998; 317 (7172): 1554-1558.

15. Ellis M, Manandar N, Manandhar DS, Costello AM. Risk factors for neonatal encephalopathy in Kathmandu, Nepal, a developing country: unmatched case-control study. BMJ 2000; 320 (7244): 1229-1236.

16. Zupan Simunek V. Definition of intrapartum asphyxia and effects on outcome. J Gynecol Obstet Biol Reprod 2008; 37 (1): 7-15.

17. Caliskan E, Doger E, Cakiroglu Y. Cord Blood Cardiac Troponin I and Creatine Kinase MB in Poor Outcomes. J Turkish-German Gynecol Assoc 2006; 7 (2): 98-102.

18. Carter BS, Haverkamp AD, Merenstein GB. The definition of acute perinatal asphyxia. Clin Perinatol 1993; 20 (2): 287-304.
19. Túrker G, Sarper N, Babaoğlu K, Gökalp AS, Duman C, Arisoy AE. Early prognostic significance of umbilical cord troponin I in critically ill newborns. Prospective study with a control group. J Perinatal Med 2005; 33 (1): 54-59.

20. Rajakumar PS, Vishnu Bhat B, Sridhar MG et al. Cardiac enzime levels in myocardial dysfunction in newborns with perinatal asphyxia. Indian J Pediatr 2008; 75 (12): 1223-1225.

21. Groenendaal F, de Vries LS. Selection of babies for intervention after birth asphyxia. Semin Neonatol 2000; 5 (1): 17-32.

22. Sarnat HB, Sarnat MS. Neonatal encephalopathy following fetal distress. A clinical and electroencephalographic study. Arch Neurol 1976; 33 (10): 696-705.

23. Cruz MA, Bremmer YA, Porter BO, Gullquist SD, Watterberg KL, Rozycki HJ. Cardiac troponin T and Cardiac Dysfunction in Extremely Low-Birth-Weight infants. Pediatr Cardiol 2006; 27 (4): 396-401.

24. O'Driscoll BR, Howard LS, Davison AG. BTS guideline for emergency oxygen use in adult patients. Thorax 2008; 63 (6): 1-68.

25. Kruse O, Grunnet N, Barford Ch. Blood lactate as a predictor for in-hospital mortality in patients admitted acutely to hospital: a systematic review. Scand J Trauma Resusc Emerg Med 2011; 19:74 http://www.sjtrem. com/content/pdf/1757-7241-19-74.pdf

26. Araujo OR, Diegues AR, Borguignon da Silva DC et al. Agreement and correlation of $\mathrm{pH}$, bicarbonate, base excess and lactate measurements in venous and arterial blood of premature and term infants. Rev Bras de Terapia Intens 2007; 19 (3): 322-326.

27. Fauchère J-C, Bauschatz AS, Arlettaz R, Zimmermann-Bär U, Bucher HU. Agreement between capillary and arterial lactate in the newborn. Acta Paediatr 2002; 91 (1): 78-81.

28. Nadeem M, Clarke A, Dempsey EM. Day 1 serum lactate values in preterm infants less than 32 weeks gestation. Eur J Pediatr 2010; 169 (6): 667-670.

29. Chanrachakul B, Chua S, Nordström L, Yam J, Arulkumaran S. Umbilical artery blood gas and lactate in healthy newborns. J Med Assoc Thai 1999; 82 (4): 388-393.

30. Suidan JS, Younq BK. Outcome of fetuses with lactic acidemia. Am J Obstet Gynecol 1984; 150 (1): 33-37.

31. Cheung PY, Robertson CMT, Finer NN. Plasma lactate as a predictor of early childhood neurodevelopmental outcome of neonates with severe asphyxia. Arch Dis Child Fetal Neonat 1996; 74 (1): 47-50.

32. Kruger K, Halberg B, Blennow M, Kublickas M, Westgren M. Predictive value of fetal scalp blood lactate concentration and $\mathrm{pH}$ as markers of neurologic disability. Am J Obstet Ginecol 1999; 181 (5, Pt 1): 1072-1078.

33. Hussain F, Glishenan K, Gray PH. Does lactate level in the first 12 hours of life predict mortality in extremely premature infants? J Paediatr Child Health 2009; 45 (5): 263-267.

34. Boniatti M, Castilho RK, Cardoso PR, Friedman G, Failkow L, Rubeiro SP et al. Acid-base disorders evaluation in critically ill patients: hyperchloremia is associated with mortality. Crit Care 2009; 13 (1): 451.

Received August 31, 2014. Accepted March 12, 2015. 